\title{
Arbutamine Hydrochloride
}

National Cancer Institute

\section{Source}

National Cancer Institute. Arbutamine Hydrochloride. NCI Thesaurus. Code C65239.

The hydrochloride salt form of arbutamine, a synthetic catecholamine with positive chronotropic and inotropic properties, used in echocardiography and diagnostic coronary angiography. Arbutamine binds to and activates beta-1 adrenergic receptors in the myocardium, thereby increasing heart rate and increasing force of myocardial contraction. By exerting a chronotropic and inotropic effect, arbutamine mimics the cardiac stress caused by exercise that may prevent adequate tissue perfusion and oxygenation, and may provoke myocardial ischemia in patients with coronary artery disease. 